\title{
Lo que dice la
}

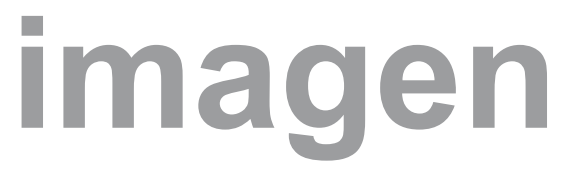

\section{Diva Velásquez}

Licenciada en Bellas Artes

Docente - Investigadora. Programa de Comunicación Social - Periodismo,

Facultad de Ciencias de la Comunicación. Uniminuto

divavelasquez@gmail.com

\section{Etimologías Clave}

Iconología. Gr.

Síntesis

Indagación sobre los aspectos que componen las imágenes, y los factores que han influido para la transformación de la interpretación de las mismas. Desde el pop, hasta la edad de los metales, este ensayo se constituye como un texto ecléctico que explora desde la diversidad como método, problemáticas del proceder visual.

\section{Synthesis}

Inquiry on the aspects that compose the images and the factors that have influenced for the transformation of the interpretation of the same ones. From the pop, until the age of the metals, this document is constituted as an eclectic text that explores from the diversity like method, problematic of proceeding visual.

$$
\begin{aligned}
& \text { Eikon }=\text { imagen } \\
& \text { Logos }=\text { discurso }
\end{aligned}
$$

Iconografía. Gr.

Imagen = latín.

cosa.

Símbolo.

Reflejo= latín.

$$
\begin{aligned}
& \text { Eikon= imagen } \\
& \text { Graphein= escribir. } \\
& \text { Imago. Representación de alguna } \\
& \text { Metáfora, representación, } \\
& \text { Reflexus. = examen, introspección, atención. }
\end{aligned}
$$

"No quiero que sea esencialmente lo mismo, quiero que sea exactamente lo mismo. Porque cuanto más mira uno a la misma cosa exacta, más se aleja el significado y mejor y más vacío se siente uno". Andy Warhol 


\section{Al parecer tenemos un afán de explicar la} imagen, de indagar y acercarnos a su significado, de buscar su poder a través de la función precisa para la cual fue concebida y diseñada, y que cobija no sólo los aspectos de la vida cotidiana, sino el carácter histórico y estético con el que fue creada. Hemos sido persuadidos por ella y sus diversos discursos a través del tiempo y hemos estado acompañados de los diferentes aspectos históricos, socio-culturales, religiosos y tecnológicos, dados por sus variadas manifestaciones y momentos de aparición para nuestro aparato visual.

En síntesis, hemos heredado un lenguaje icónico que encuentra su condicionamiento en la manera como ha sido percibido, y sin embargo, insiste en dar una significación compleja, que depende de las múltiples experiencias del ser, captadas por la conciencia y el pensamiento. Es a través de la Teoría de la Imagen, que se trata de definir si corresponden estas construcciones a imágenes mentales o elaboraciones de carácter cultural, que se articulan como un espacio de reflexión que reconoce en toda imagen, la existencia de un discurso.

Esto nos lleva a dividir la problemática de la imagen en dos vectores, por un parte, su significación - incluso en términos de lo que se considera una gramática plástica -; y por otra, la percepción mediada por las interpretaciones que le ha otorgado a su proceder e interpretación, las narraciones históricas.

Sobre la problemática inicial, se puede considerar la imagen como una imitación aparente de la realidad y cómo ésta afecta su significación. Consideración que obedece a una concepción neoplatónica de la representación, debido no sólo al mundo de las proyecciones de las sombras, sino al constante bombardeo al que cotidianamente nos vemos enfrentados en la era visual, que de ninguna manera ha permitido, ver con claridad y sin mediaciones la esencia del conocimiento y la estructura pura del discurso visual; en este sentido la imagen podría ser interpretada como una suerte de nueva imitación de los modelos y las formas recurrentes a las que se ve afectado el aparato visual, así como la de los estadios de la imagen que desbordan lo estilístico y los histórico; son aparentes, en el sentido en el que la

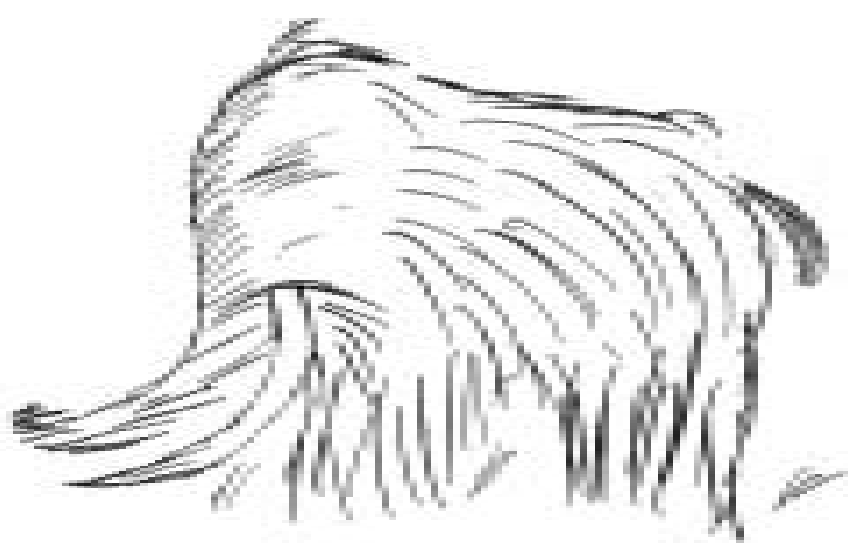



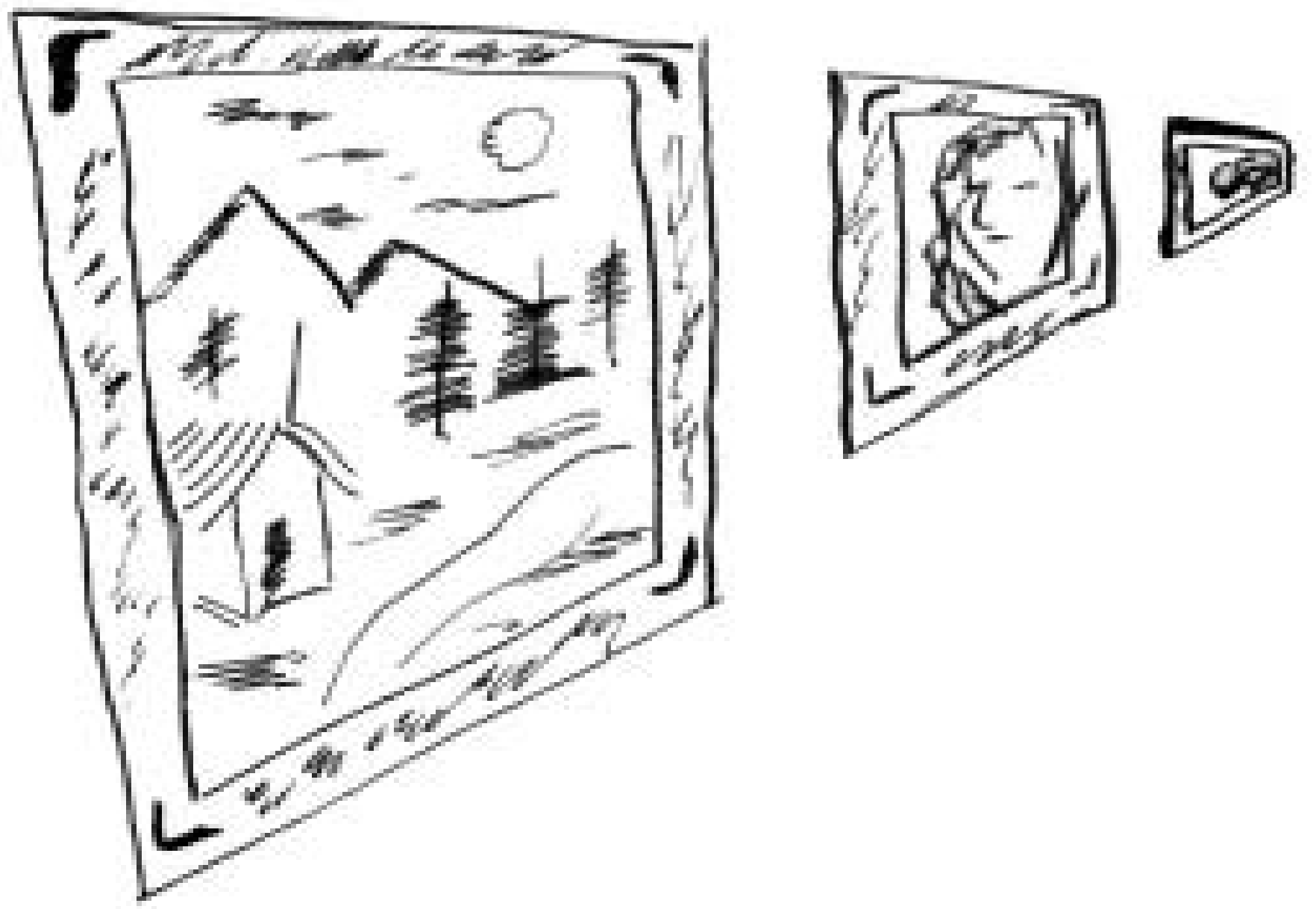

imagen oculta y adorna la esencia de los objetos y las formas, sobre todo en una época atiborrada de imágenes en diversos medios. Es posible pensar que todas estas problemáticas de procederes y concepciones de la imagen, afectan el significado de las mismas. En cuanto al proceder, se puede abordar una premisa: el avance de las tecnologías reproductivas de la imagen, ha permitido construir un complejo sistema de gramatike visual, que están compuestas por el espectro de lo óptico y de lo conceptual.

En este sentido, la gran gama de posibilidades técnicas, ha logrado difuminar el horizonte de lo considerado como parte de los elementos visuales - tales como: la 
forma, la textura, el color, la perspectiva, línea, punto, plano, etc. -, de dicha gramática. Es entonces cuando la máquina se confunde con el hombre, así como, la huella y el gesto que caracterizó durante varios decenios la producción y autoría de la imagen, lo que la identificaba y particularizaba. Bajo el horizonte conceptual, se han permeado diversos discursos, que del mismo modo se han confundido, generando un inmenso palimpsesto de lecturas y órdenes que configuran la imagen resultante.

En segunda instancia, se ha indagado a través de un conjunto de ideas que intentan analizar la imagen, y el hecho de construirlas a partir de referentes que tratan de aplicar fenomenologías, aconteceres y crónicas cotidianas. Así, teorías para explicar y fundamentar la imagen desbordan las grandes narraciones históricas y se remiten a las pequeñas y paralelas narraciones, una óptica más objetiva e incluso "traumática"1 de las que se ven sometidas las múltiples lecturas de la imagen actual.

Es de reconocer que la historia como metanarración, ha sido la madre de este trauma, pues establece la relación entre representación artística y la realidad externa, ilusoria, que ha sido dada a través de esquemas figurativos, con un valor codificado correspondiente a los convencionalismos propios de las artes. Este método sólo puede ser efectivo no tanto en la representación, como lo hemos entendido hasta el momento, sino que el trauma requiere de la repetición para mante-

${ }^{1}$ Véase: LACAN, Jacques, Cuatro conceptos fundamentales del psicoanálisis, Barcelona, Barral, 1977, págs. 77-64. Es de considerar en este punto la posición de Lacan en torno a lo traumático, cuando lo define como un encuentro fallido con lo real. Y no es de extrañarse, que esta sea la relación que actualmente establezcamos con la imagen y en general con cualquier producto visual que involucre otras técnicas.

${ }^{2}$ Véase: FOSTER, Hal, El retorno de lo real, la vanguardia a finales de

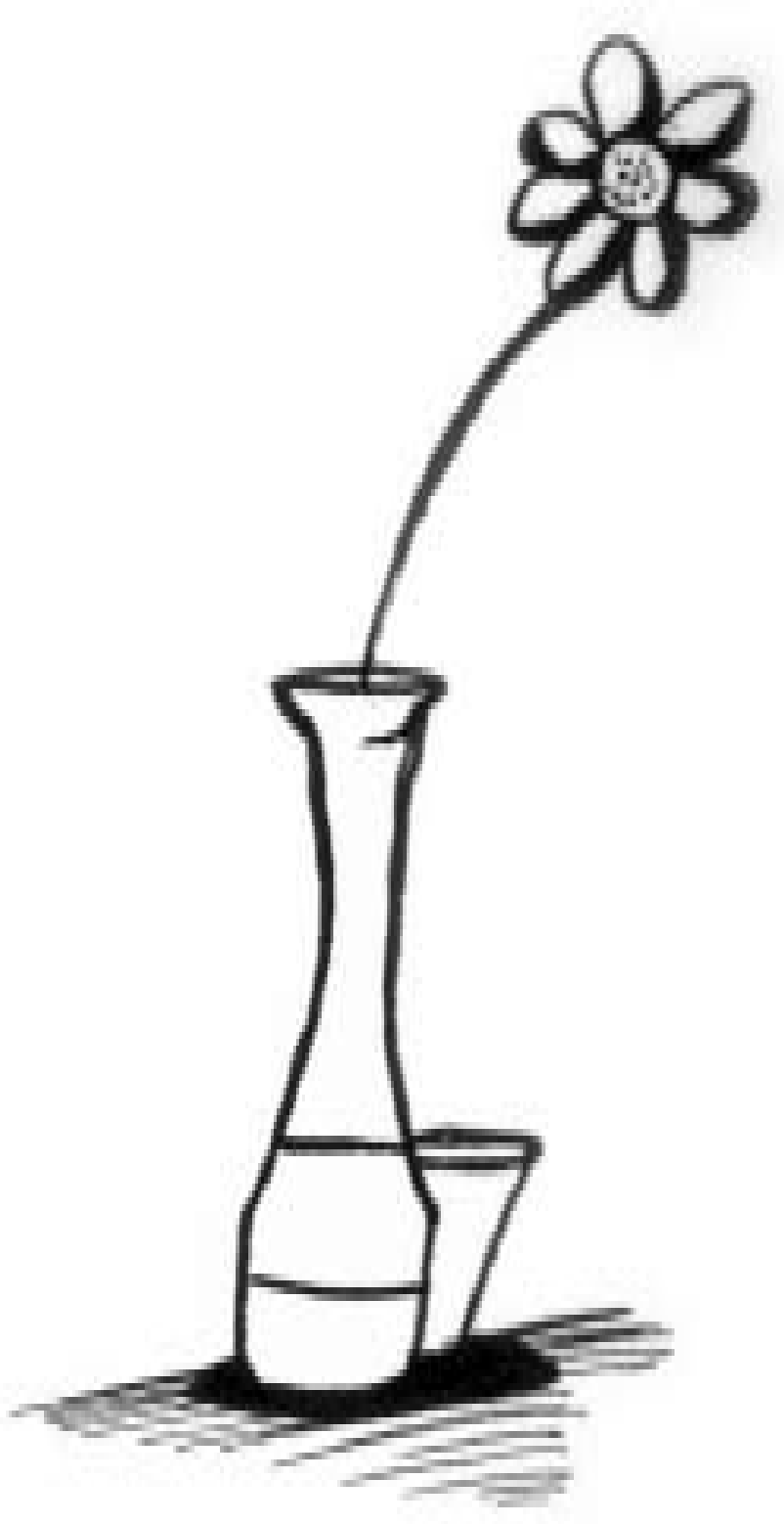


ner ese valor, no es de extrañarse en este caso, que por ejemplo, durante la segunda mitad del siglo XX, el arte no se preocupara tanto por crear nuevos objetos con nuevos significados e incluso metodologías, sino que se apoyara en la recolección de imágenes y dis- cursos de épocas pasadas ${ }^{2}$. En particular el arte pop y el apropiacionismo fueron las prácticas que más se preocuparon por este respecto, con su recurrencia al final cíclicamente volvían a la reafirmación del trauma causado por lo real.

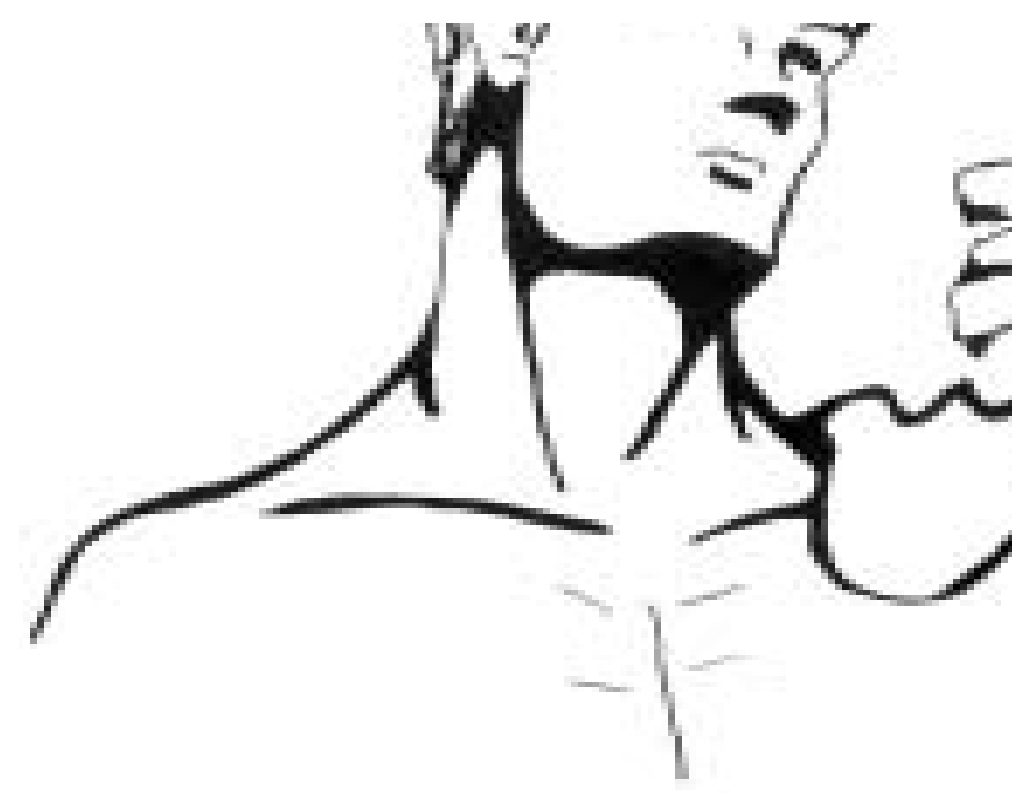

siglo, Madrid, Ed. Akal, 2001, págs 129-148.

${ }^{3}$ BRUSATIN, Manlio, Storia delle immagini, Torino, Italia, Einaudi, 
La opción figurativa, está regulada por algunas articulaciones y esquemas, de lo que ya conocemos por referencias históricas, dándole así un valor a una acción que eliminaría la idea de una visión inocente y natural, pero al mismo tiempo buscaría un replanteamiento que haga alusión a un tipo de discurso que se establece a través de un recorrido de la existencia de la imagen, en sus estructuras más fundamentales, como anunciaciones visuales, que en definitiva estudiarían diferentes puntos de vista y a su vez son complementarios como objeto de estudio de la imagen y dependerían de dos elementos subjetivos: el lenguaje y la mirada.

Así como reevaluamos el carácter de veracidad de la historia durante el siglo XX, y el cómo comprendemos la imagen como elemento comunicativo y de demanda neocapitalista ahora en el siglo XXI, surge de inmediato la problematización del concepto de lo real, que ha sido percibido de manera diferente, a medida que se han dado los cambios de la concepción y percepción del mismo, con el paso del tiempo y la transformación de la mirada. El concepto de lo real preocupa y afecta directamente la interpretación y construcción de los discursos de la imagen y cómo se articula la misma, desde lo que podríamos considerar como la civilización de la imagen.

La verdadera búsqueda de la imagen desde lo real, parte de una semejanza al ídolo, a la naturaleza, a las analogías de reconocimiento de su carácter inmediato, en la apariencia que refleja con ése afán de mímesis, se identifica, reproduce, modifica y re-coloca una nueva identidad como nueva realidad. En este punto se considera de nuevo el mito de las sombras al igual que la

1992, pág. XVIII.

${ }^{4}$ Op. Cit., pág. XXI propuesta platónica. Al respecto Manlio Brusatin versa: " La verità di un'immagini nasce della sua suggestione che è la sua estensione possibile, lo spazio dove si allunga la sua ombra”3. Dicha opacidad anclada al deseo de mirar imágenes, buscando un reconocimiento en el juego de las mismas, e identificando su conexión con la palabra, hecho que complejiza e incluso enriquece su lectura. Si cada individuo necesita un reconocimiento, un reflejo de sí mismo sobre el objeto de su deseo, lo hace a través de las imágenes y rituales, además exponiéndose a entidades icónicas. Estas visiones en la mayoría de los casos poseen un destino afortunado, el de aflorar, informar; y otras tienen la necesidad de reflejarse, pero esa búsqueda de la verdad de la imagen, difundida por los medios predominantes productores de imágenes e imaginarios, pueden complejizar radicalmente la veracidad, debido a que somos una civilización de la imagen que debe recordar lo elementos arqueológicos que componen el tejido de la imagen, compuestos por su propia memoria, sin dejar atrás los momentos históricos en que fueron producidas, y las prácticas estéticas que deben ser valoradas desde la óptica de su época de producción.

Si escuchamos a las imágenes: "Las imágenes hablan solas", o nosotros queremos que se comuniquen. Aunque esta afirmación es aplicable muchas veces solamente a las imágenes de carácter publicitario, es posible encontrar en algunos casos contradicción, en un momento en el cual nos hemos visto sometidos a la saturación y al trauma, que el aparato visual e incluso discursivo sólo encuentra respuesta en la confusión y entropía de la imagen. En este sentido es válido pensar que este presupuesto, esta mediado por los sometimientos visuales a los que nos enfrentamos cotidianamente; no es de extrañarse que un videojuego,

${ }^{5}$ DEBRAY, Regis, Introducción a la Mediología, Barcelona, España, 

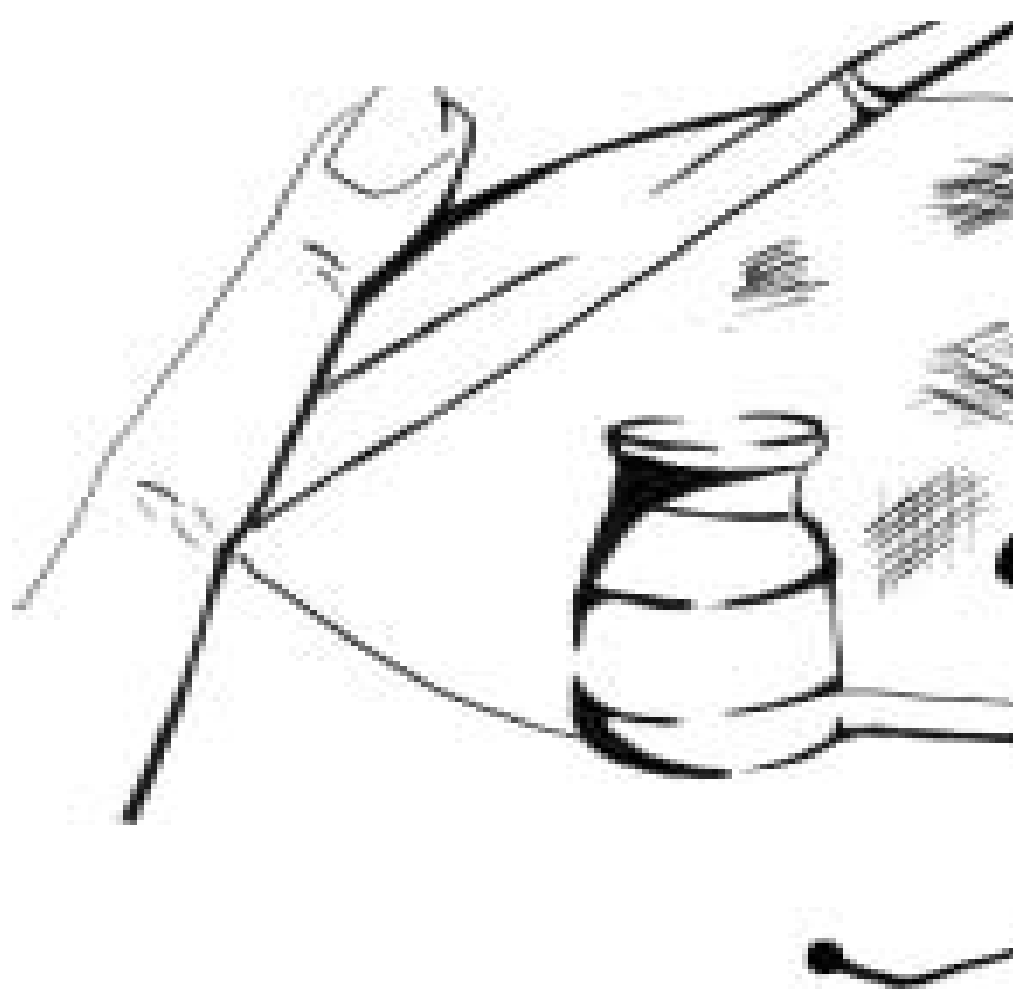

o la interfaz de un software, para una persona de otra generación distinta a la que creció dentro de este orden visual, cause algún tipo de reacción adversa, generando finalmente una anomalía en la lectura del discurso visual planteado. Este ejemplo es equivalente al caso de la introducción de nuevas temáticas que escandalizan al espectador deshabituado al tratamiento de ciertos fenómenos culturales inherentes al ser humano, heredadas recurrentemente sobre todo en la estética de ciertos géneros del rock.

El hombre elabora sus imágenes con diversos materiales costosos o baratos, para contemplarlas, adorarlas o utilizarlas cotidianamente y en algunos casos esa producción se difunde creando esquemas, modelos con los que algunas civilizaciones se identifican.

Al participar en la difusión de las imágenes por medio de 
los diferentes elementos icónicos y anicónicos, siempre existirá un carácter simbólico en las mismas, siempre estaremos expuestos a la ruptura simbólica, a la pérdida. Este recurso ha perdurado en la religión: monoteístas y politeístas, dejan ver las tradiciones, instituciones, y sobre todo el tutelado de la eternización y exaltación, con un control deliberado de la imagen, en donde el discurso iconológico acompaña al iconográfico, donde adorar y servir, forman parte de sus características, enajenando - gracias a su embelesamiento-, algunos de los factores que influyen aún la historia de la imagen.

Su destino, como en el que algunas se vuelvan más productivas al ser construidas y colocadas sabiamente dejando señales distintivas, develan prácticas rituales, que adquieren un carácter eficaz e indisoluble con respecto a su propio destino privilegiado.

La imagen permanece o desaparece según los materiales con los que haya sido construida. Dependiendo de dichos materiales perdura como motivo de contemplación y adoración, difundiéndose como modelos que ejemplifican características creadas por las diferentes civilizaciones y que permiten su reconocimiento; por ejemplo, la imagen del cuerpo humano encubre un sistema de custodia a su destino; así la voluntad del ícono puede estar dada por mecanismos de difusión e intercambio de productos dados por la voluntad cargada de diferentes ideologías, producidas por los distintos regímenes que permiten entender, sistemas de organización, de violencia, de destrucción, de estratificación social, de razas y comportamientos.

Durante mucho tiempo la imagen vive gracias a la religión, y sobre todo a regímenes ortodoxos con sus tradiciones, que apoyadas por las instituciones tutelan, exaltan y eternizan elementos de poder en las imágenes. Difundiendo y asociando religión y poder se muestran elementos de continuidad en el destino y utilización de la historia de las imágenes, que construyen sabiamente múltiples significados, a veces dejando abiertos algunos significados, que según el momento pueden ser entendidos como señal distintiva o afín a sus características.

Cuando la imagen es favorecida por las culturas que le dan una mayor difusión, adquieren estilos propios, y reclaman su propia distinción. Como confrontación, como la necesidad de trazar huellas con su propio cuerpo sobre diferentes materiales. Piedra, arena barro, son los elementos de un primer acercamiento a la creación / representación visual, y que se ligó de antaño, al cambio dado por el estímulo motriz sobre la mano, además de la oposición del dedo pulgar y la posibilidad de crear su propia pinza para agarrar los elementos que lo rodean.

Esta primera construcción de un imaginario visual estaba articulada a través de símbolos y signos. Los primeros entendidos como imágenes que se separan de una percepción inmediata y se anclan en la memoria a diferencia del signo que se considera como un hecho oculto que corresponde o remite a otro. En sumatoria, se pueden interpretar como imágenes con profundo significado, y que pueden traducir —ante nuestra óptica-, el poder que depositaba el hombre en estas producciones visuales.

Para anticiparse y proyectar imágenes que permiten acercarse al hombre cazador en su entorno, su experiencia es representada a través de marcas, como instrumento del desarrollo de la conciencia humana. El hombre ha podido comprender paso a paso la naturaleza de las cosas por medio del reconocimiento fragmentario de sus experiencias más significativas y así una imagen rupestre recuerda una mirada que se 
conserva en la memoria, interpretada en ocasiones como la voluntad de vivir a través de una imagen que se complementa con elementos mágicos, de intensa emoción.

La presentación del mundo de las imágenes en su sentido representativo nace como un forma de acción, sobre la realidad, y la capacidad de asombro del hombre primitivo, se constituyó en una forma mediatizada de percepción que más que su función fuera comunicar y transmitir revelaba la importancia que el ángulo de visión ofrece: "Una transmisión es una comunicación optimizada por un cuerpo, individual y colectivo, en el doble sentido de "éste es mi cuerpo "y de "los grandes cuerpos"5 y que marca un proceso transmitido por tradición generacional, a través del tiempo.

"El mayor triunfo del hombre sobre las cosas es el haber sabido transportar hasta el día siguiente los efectos y los frutos de la labor del día anterior. La humanidad sólo ha conseguido erguirse lentamente sobre los montones de lo que dura"6. Así es como se articula el mito o el relato histórico le da legitimidad a sus diversos valores dentro del marco del espacio-tiempo, a través de lo perenne, como elemento fundamental de la memoria.

A partir de lo que representa, se incursiona el dibujo, que se va dando en proceso de aumento en cuanto

Paidós, 2001. A este respecto es importante resaltar de nuevo, la corporalidad física, en cuanto a que sin un vehículo contenido de sentidos, la labor comunicativa con la imagen no sería por lo menos, un hecho. Por otra parte, todo este discurso, no sería posible de no establecerse un valor "real", entre las herencias culturales, que se transmiten de generación en generación y que le atribuyen poder a la imagen.

${ }^{6}$ Op. Cit. pág 18.

${ }^{7}$ PANOFSKY, Edwin, El significado en las artes visuales. Madrid, España, Alianza, 1991, págs. 46-75. densidad de la imagen, con toda su carga ritual. Identificación que según Panofsky ${ }^{7}$ y que denominó iconografía e iconología, disciplinas que se ocupan, tanto del objeto de interpretación en el acto de interpretación, como el bagaje de dicha interpretación, del asunto o significación, en contraposición a su forma. En éste nivel pre iconográfico, se inicia reconociendo en las formas, lo fáctico, lo expresivo entre de los objetos naturales y la identificación con las relaciones primarias dadas entre ellos. Así las "formas puras", señalan la experiencia directa con el mundo, identificando los motivos artísticos también como condiciones estilísticas propias de una época determinada y bautizados bajo el presupuesto de conceptos y temas.

Los valores simbólicos, según Panofsky, van vinculados de una manera muy profunda a las convencionalidades aplicadas a la práctica del arte y que posteriormente por el uso son consideradas como tendencias. Éstas se han interpretado bajo condiciones históricas diferentes, expresadas bajo temas específicos y que se conocerían después como iconología.

Un periodo posterior como el Neolítico, está determinado por el amplio paso y desarrollo de la sensibilidad artística, quizás con una mayor conciencia plástica y una unificación de la experiencia sensible de la realidad con selección de lo significativo, con elementos que señalan su cambio de vida de los conflictos entre los estilos de vida nómada a la sedentaria. Lo anterior como una muestra evolutiva/ cognitiva del hombre, que se manifiesta a través de la organización de las ciudades y la huella a través de los diferentes oficios; picapiedrería, curtiembres, tejidos, cestería, cordelería, alfarería, orfebrería, tintorería y culinaria. Metalurgia, como paso a la edad de los metales. Todas como manifestaciones que revelan a través de las nuevas tecnologías, las diferentes manifestaciones y represen- 
taciones de las civilizaciones dependientes no sólo del cultivo de las tierras, del desarrollo del comercio, del intercambio de productos, de la necesidad de abstraer inventando las matemáticas, asimilando lo complicado en la aplicación de los sistemas de abstracción que dan origen también a los nuevos métodos de escritura, a la geometría, etc.

En la edad de los metales, así como el hombre se convierte en el hacedor de su entorno, así también en esa búsqueda de dominar a la naturaleza, selecciona y prueba, construye, encuentra la diferencia entre modelar y construir; entiende la necesidad de la comunicación de los caminos, la estructura social, la construcción, sus avances y las posibilidades constructivas en los sistemas de fuerzas, su desarrollo, los nuevos inventos: el inicio de la ingeniería.

La utilización y el mejoramiento de sus herramientas, con la aparición de los metales, su mejoramiento y optimización con el descubrimiento de la aleación, proceso mental de mayor análisis que puede ser considerado como triunfo del método intelectual. El metal determina el poder y así el paso del cobre al hierro, muestra no sólo su utilización, sino la manera como se descubre la constitución del mundo de la materia a partir de sus elementos.

\section{A modo de conclusión}

Son aún, muchos momentos de la imagen por los que hace falta pasar, nombrar y extender en ideas e incluso conexiones, que para algunos estudiosos se consideran inexistentes. Sería interesante plantear una problemática que conecte sucesos pasados de la imagen, con procederes actuales de su producción. El cambio discursivo al que se ha visto expuesta, en algunos casos haría pensar en su lenta muerte, debido a su repetició y a la relación traumática que establece con el espectador. El atiborramiento y exceso, deduce una falencia discursiva, y un sinfín de interpretaciones para el espectador, para el consumidor. La imagen durante varias épocas articuló y construyó toda una variedad de historias y mitos, es actualmente en donde podemos pensar en una herida debido a lo disfórico de su producción, sin embargo, la imagen aún, pese a todo, posee el poder de construir identidades, por lo secularizada que se encuentra nuestra sociedad.

\section{Bibliografía}

BRUSATIN, Manlio, Storia delle immagini, Torino, Italia, Einaudi, 1992.

DEBRAY, Régis, Vida y muerte de la imagen. Historia de la mirada en Occidente, Barcelona, España, Paidós, 1998.

GOMBRICH, E.H., Historia del arte, Alianza, Madrid, España, 1992.

Los usos de las imágenes. Estudios sobre la función social del arte y la comunicación visual, Fondo de Cultura Económica, México, 2003.

GOMBRICH, E.H. y ERIBON Didier, Lo que nos dice la imagen. Conversaciones sobre el arte y la ciencia, Bogotá, Colombia, Norma, 1993.

PANOFSKI, Edwin, La Idea. Contribución a la historia de la teoría del arte, Cátedra, Madrid, España, cátedra 1989.

La perspectiva como forma sim-

bólica, Barcelona, España, Tusquets, 1990.

El significado en las artes visuales, Madrid, España, Alianza, 1991. 